\title{
Ameloblastic Fibroma of Mandible - A Case Report
}

\author{
Allenki Shravya ${ }^{1}$, Pavan Kumar Batchu², Haripriya Chari ${ }^{3}$, Vuyyuru Vidya Devi ${ }^{4}$
}

Quick Response Code

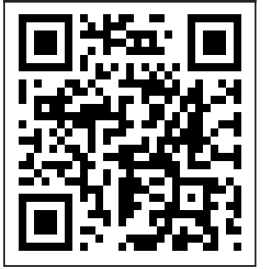

doi: $10.5866 / 2017.9 .10128$

1Post Graduate Student

${ }^{2}$ Prof \& HOD

${ }^{3 \&}{ }^{4}$ Senior Lecturer

Department of Oral and Maxillofacial Surgery

Kamineni Institute of Dental Sciences

Narketpally, Nalgonda

\section{Article Info:}

Received: April 11, 2017

Review Completed: May 10, 2017

Accepted: J une 10, 2017

Available Online: J une, 2017 (www.nacd.in)

(c) NAD, 2017 - All rights reserved

Email for correspondence:

shravya.allenki@gmail.com

\section{INTRODUCTION}

Ameloblastic fibromas are a rare variety of benign odontogenic tumors composed of prol iferating odontogenic epithelium embedded in a cellular ectomesenchymal tissue resembling dental papilla. ${ }^{1}$ It was first described by Kruse in 1891 and later classified as a separate entity by Thoma and Goldman in 1946.2,3 It can appear in either the maxilla or mandible, with the posterior region of the mandible as its most common anatomic site.Diagnosis is generally made through routine radiographic examinations performed to look for an impacted tooth as a cause of the swelling. ${ }^{4}$ Conservative excision seems to be the treatment of choice for ameloblastic fibroma. A modified block resection, rather than a curettage or simple excision, has been suggested. ${ }^{5}$
ABSTRACT:

Ameloblastic fibroma is a relatively uncommon benign tumor of mixed odontogenic origin that can occur in either the mandible or the maxilla, but is most frequent in the posterior region of mandible. It usually occur in the first two decades of life and associated with impacted tooth, causing a delay in eruption or altering the dental eruption sequence.This report presents a case of amel oblastic fibroma in a 45 year old male who reported with a swelling in the right lower jaw region since 6 months. Segmentalresection of the mandible was carried out and reconstruction was done with iliac crest graft. Long term prognosis showed satisfactory healing and good facial esthetics.

Key words: Ameloblastic fibroma, mandible, odontogenic tumor

\section{CASE REPORT}

A 45 year old male patient reported to the department of oral \& maxillofacial surgery, with the chief complaint of a swelling in the right lower jaw since 6 months.The swelling was insidious in onset and gradually increased to the present size. Extraoral examination revealed adiffuse swelling measuring $2 \times 2 \mathrm{~cm}$ on the right side of the mandible, extending anterio-posteriorly $2 \mathrm{~cm}$ posterior to the right corner of the mouth to the angle of the mandible (Figure 1). Swelling was not associated with any symptoms like pain. Intra oral examination revealedswelling extending from distal aspect of second molar to the anterior border of ramus of the mandible causing vestibular obliteration which is non tender and hard in consistency. On lingual aspect, swelling was mildly perceptible andthe 


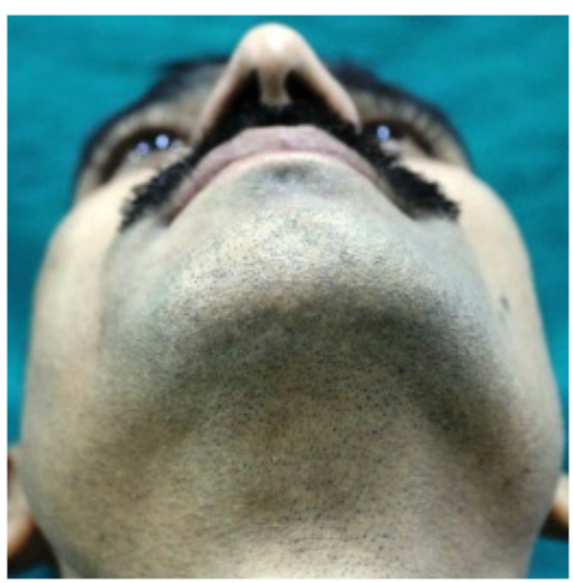

Figure 1: Preoperative clinical photograph showing swelling in the right angle region

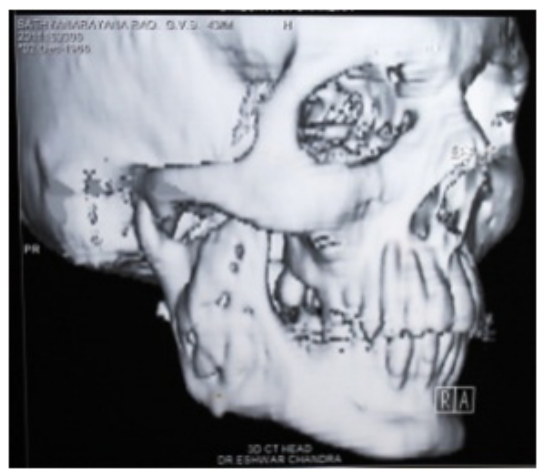

Figure 3: Preoperative 3D CT showing cortical expansion due to amel oblastoma involving the right ramus

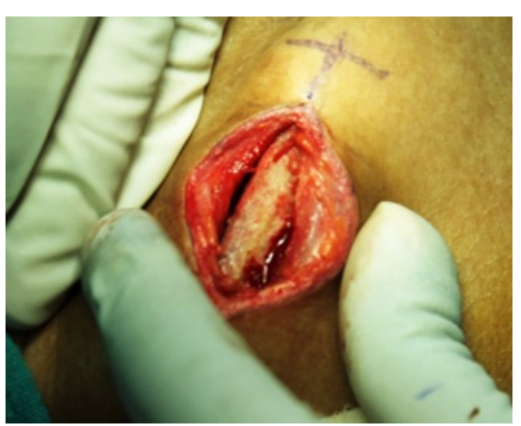

Figure 6: Intraoperative photograph the harvesting of iliac graft

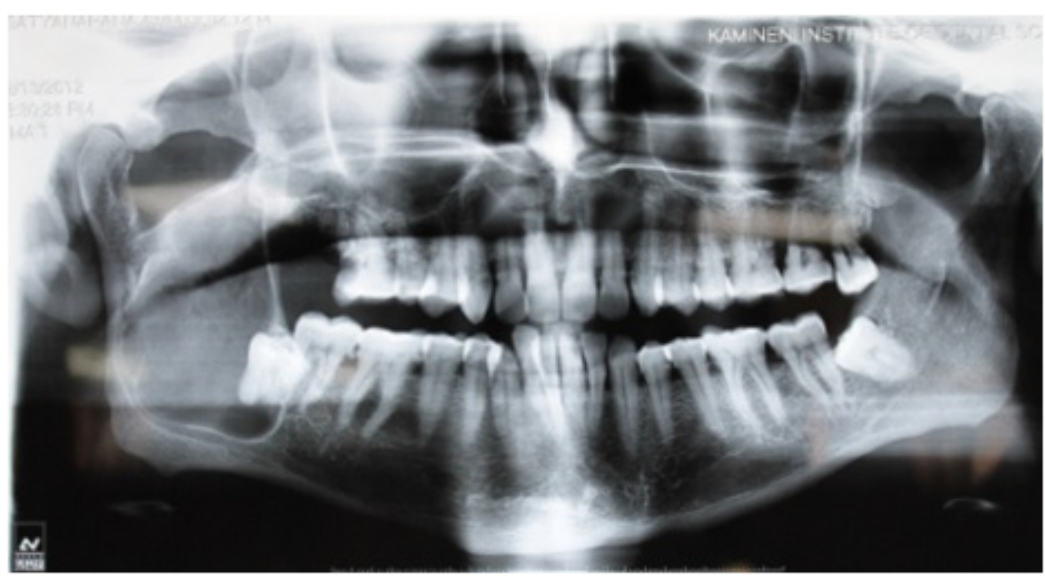

Figure 2: Preoperative radiograph showing radiolucency involving the right ramus and angle of the mandible

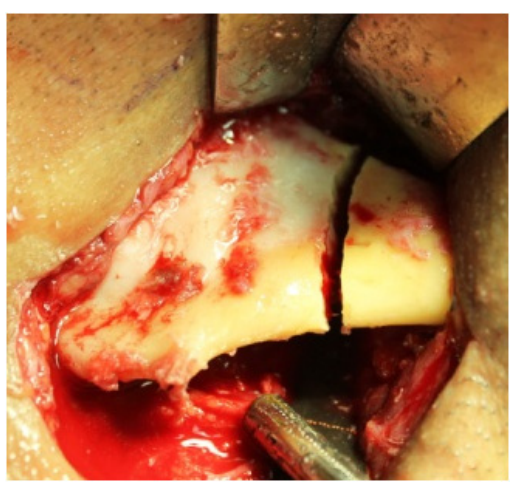

Figure 4: Intraoperative photograph showing the osteotomy cut for the resectiøesected ramus with the ameloblastoma of the amel oblastoma

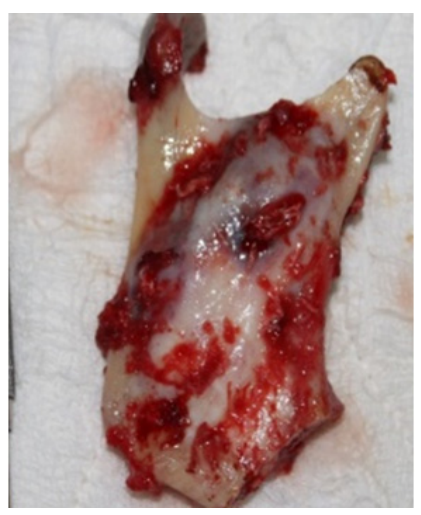
lesion

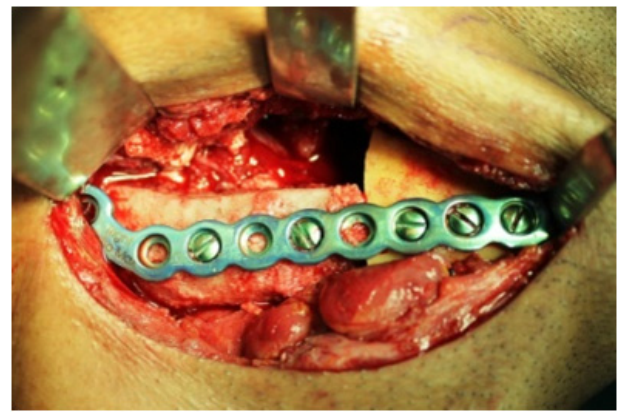

Figure 7: Intraoperative photograph showing reconstruction of the resected segment with iliac graft and reconstruction plate

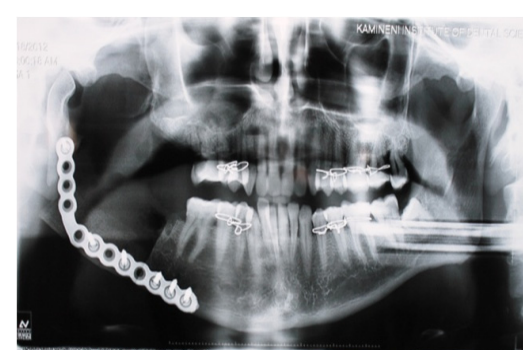

Figure 8: Postoperative radiograph showing reconstruction of the resected segment with iliac graft and resected condylar segment secured with reconstruction plate 
overlying mucosa was intact and normal in color. Orthopantomograph revealed a well defined unilocular radiolucent lesion with sclerotic radiopaque marginsextending from 37 , involving impacted third molar , ramus up to coronoid process and subcondylar region of right side of mandible (Figure 2). The CT findings revealed expansion of buccal and lingual cortical plates andperforation of the lateral aspect of ramus of the mandible (Figure $3)$. Based on the clinical and radiological examinations, a provisional diagnosis of ameloblastoma was made. An incisional biopsy was done providing a diagnosis of amel oblastic fibroma. Considering the aggressive nature of ameloblastic fibroma, resection of the lesion followed by reconstruction with iliac crest graftwas planned. Submandibular incision was given $2 \mathrm{~cm}$ below inferior border of right side of mandible and layer wise dissection done. Facial artery and vein were identified and ligated. The lesion was exposed and the segmental resection of the mandiblewas carried out using a gigly saw with a safety margin of $1 \mathrm{~cm}$ extending anteroposteriorly from distal aspect of right first molar region to condyle along with the coronoid process (Figure 4 and 5).

For harvesting the iliac graft, a sub-crestal window technique was performed by making skin incision over the anterior iliac crest. Muscles were stripped sub-periosteally from the ilium, and the cortico-cancel lous block of length $4 \mathrm{~cm}$ was harvested by using osteotomes (Figure 6). Following the removal of the bone graft, hemostasis was achieved and a drain was placed into the site followed by closure of the periosteal layer. The muscle layers and subcutaneous tissue were closed with 3-0vicryl. The skin was closed with 3-0 prolene (interrupted sutures).

The reconstruction plate was contoured and the condylar segment from the resected specimen was sectioned and fixed as a free graft. Stabilization of the harvested iliac crest graft was done using $2.5 \mathrm{x}$ $10 \mathrm{~mm}$ titanium screws (F igure 7 and 8 ). Layer wise closure was done with 3-0 vicryl and 5-0 prolene extra orally). Excisional biopsy confirmed the diagnosis as ameloblastic fibroma.The patient has been followed up periodically till 3 years. The outcome has been aesthetically satisfactory and there have been no signs of recurrence.

\section{DISCUSSION}

Amel oblastic fibroma is a true histologicbiphasic tumor because epithelial and mesenchymal components are part of the neoplastic process.
According to Reichart and Philipsen, male to female ratio was 1.4:1. Mean age of occurrence is 14.8 years with a range of 0.5 to 62 years. It is a slow growing tumor which is commonly located in the mandibular posterior area and is often associated with an impacted tooth. Philipsen et al. proposed that the innocuous behavior of the lesion does not justify aggressive initial treatment but rather meticulous surgical enucleation with close clinical follow-up. ${ }^{4}$ Muller et al reported that since 1960, 44\% cases of ameloblastic fibrosarcoma (19/43) had arisen from ameloblastic fibroma. ${ }^{6} \mathrm{~A}$ recurrence rate of $43.5 \%$ and $18 \%$ was reported by Trodahl and Zallen, respectively. Gundlach was of the opinion that simpleenucleation would not be sufficient for ameloblastic fibroma. ${ }^{7}$ An aggressive surgical treatment is, therefore,suggested by some authors because of the possibility of malignant transformation of an ameloblastic fibroma to an ameloblastic fibrosarcoma. A modified block resection of the mandible with the placement of an immediate autol ogous bone graft is treatment option for an extensive tumor and/or multiple recurrences. Complete excision of the tumor with long-term clinical and radiographic follow up is highly recommended. ${ }^{8}$

\section{REFERENCES:}

1) Kramer IR, Pindborg J J, Shear M. Histological typing of odontogenic tumours. Springer Science \& Business Media 1992; 2988-94.

2) Kruse A. Ueber die Entwickelung cystischer Geschwülste im Unterkiefer. Virchows Archiv 1891; 124(1):137-48.

3) Thoma KH and Goldman HM. "Odontogenic tumors-a classification based on observations of the epithelial, mesenchymal, and mixed varieties,". Am J Pathology 1946; 22(3):433-71.

4) Trodahl J N. Ameloblastic fibroma - A survey of cases from the Armed Forces Institute of Pathology. Oral Surg Oral Med Oral Pathol 1972; 33:547-58.

5) Philipsen HP, Reichart RP, Pratorius F. Mixed odontogenictumors and odontomas: considerations on interrelationship. Review of the literature and presentation of 134 new cases of odontomas. Oral Oncol 1997; 33:86- 99.

6) Kobayashi K, Murakami R, Fujii T, Hirano A. Malignant transformation of ameloblastic fibroma to ameloblastic fibrosarcoma: case report and review of the literature. J Cranio Maxillofac Surg2005; 33:352-5.

7) Muller S, Parker DC, Kapadia SB, Budnick SD, Barnes EL. Ameloblastic fibrosarcoma of the jaws: a clinicopathologic and DNA analysis of five cases and review of the literature with discussion of its relationship to ameloblastic fibroma. Oral Surg Oral Med Oral Pathol Oral Rad End 1995; 79(4):469-77.

8) Peter AR and Hans PP. Odontogenic Tumors and Allied Lesions, Quintessence Publishing, Hanover Park, III, USA, $1^{\text {st }}$ edition, 2004. 